\title{
Adverse drug reactions and drug errors
}

\author{
Raymond Tallis \\ Professor of Geriatric Medicine, University of Manchester Department of Geriatric Medicine, Hope Hospital, \\ Eccles Old Road, Manchester M6 8HD, UK
}

\section{Editorial}

A recent editorial in the British Medical Journal, 'Is there a cure for drug errors?', addressed an important issue. ${ }^{1}$ It pointed out that drug errors are both avoidable but difficult to avoid. And it made many eminently sensible recommendations. All those who are part of the prescribing and dispensing process should be aware of their fallibility. Junior doctors should have ready access to a drug information service and their prescriptions should be checked by senior medical staff, by the pharmacists, and by the nurses who give the drugs. The article pointed out also that patients, too, could take responsibility for their medication. Finally, it suggested 'critical incident reporting' as a means of gathering data that uses mistakes constructively, without threatening those who admit to them.

The relevance of prescribing errors to anyone interested in the health care of elderly people is obvious. The potential for such errors is much greater when accurate diagnosis is often more difficult and patients have multiple conditions that may justify the issuing of multiple prescriptions for drugs that may interact or, indeed, be contraindicated.

The principles of appropriate prescribing for older patients are set out clearly in a review in this issue by Tully ${ }^{2}$ who also underlines the vulnerability of elderly people to adverse drug reactions (ADRs). The prevalence of ADRs is alarming. In one study of elderly people attending outpatient clinics, up to $50 \%$ suffered ADRs and $2.5 \%$ of consultations were caused by an ADR. ${ }^{3}$ Williamson and Chopin in their classic study found an incidence of ADRs in those taking prescribed drugs of $15.3 \%{ }^{4}$ These were the sole cause of admission in $2.8 \%$ and a contributing cause in $7.7 \%$. A more recent study in Exeter reported a slightly lower figure of $11.4 \%$ of patients suffering from ADRs; however, the proportion of admissions primarily caused by ADRs was comparable, namely, $2 \% .^{5}$

For a long time, this burden of therapy-related illness has been attributed to the special characteristics of elderly patients: the way they handle drugs; their increased sensitivity to drugs; the problems of multiple pathology; and their supposed propensity for poor compliance. Recent studies, however, have shown that compliance is no worse in elderly than in younger people. ${ }^{6}$ Multiple pathology should not be a problem so long as prescribing is careful and accurate. And pharmacokinetic and pharmacodynamic changes related to aging do not of themselves inevitably bring about pharmacological disaster if dosages are appropriately tailored.

We therefore need to switch our attention from the distal end of the prescription (the patient) to the proximal end of the prescription (the doctor). Our own studies, conducted over more than a decade, have shown that inappropriate prescribing is common in patients admitted to hospital, ${ }^{7}$ in those presenting to accident and emergency departments, ${ }^{8}$ in long-term care $^{9}$ and in Part 3 residential homes. ${ }^{10}$ More recently, Willcox and colleagues found that almost $25 \%$ of elderly patients living in the community were prescribed inappropriate drugs. ${ }^{11}$ In a Canadian study $53 \%$ of elderly patients experienced one or more events of 'high-risk' prescribing and $47 \%$ of questionable prescribing. ${ }^{12}$

What evidence, however, is there that inappropriate prescribing is a major cause of adverse drug reactions? We addressed this question in a study which looked at both the incidence of adverse drug reactions and inappropriate prescribing in patients who were presenting for admission to a large teaching hospital. ${ }^{13}$ Over $10 \%$ of patients were taking contraindicated drugs and over a quarter were taking drugs that were deemed to be unnecessary. Moreover, patients on contraindicated or unnecessary drugs had a significantly higher ADR rate than those not on such medication. We estimated that just under half of adverse drug reactions and of drug-related hospital admissions were due to inappropriate drugs.

Prescribing errors seem to have been grossly 
underestimated as the most important of the various causes of adverse drug reactions in older people. This may be because the agenda for geriatric pharmacology has often been driven by clinical pharmacologists and others who would be spontaneously more interested in 'high-powered' investigations into pharmacokinetics and pharmacodynamics, rather than such homely things as 'cockups'.

Even those who recognize the importance of drug errors in the aetiology of iatrogenic disease suggest the wrong treatment. There is a good deal of rhetoric about 'education' and 'increasing knowledge' of prescribers. The truth is that there is a limited storage capacity to the human cerebral cortex and even the knowledge that is stored in it may not be mobilized at the time when it is needed. Our 'passive' knowledge-base far exceeds our 'active' knowledge.

What is required, as I and my co-workers have argued over the years, ${ }^{14}$ is the provision of knowledge at the time of need. The knowledge required is of two sorts: knowledge of clinical pharmacology and therapeutics; and knowledge of the individual patient. This should be provided on-line, and the only way in which this can be done is by use of computer systems which can effectively ensure that the two bodies of knowledge interact, so that drug interactions and contraindications, for example, may be detected.

It is frustrating, at a time when we have computers that are able to steer spacecraft from millions of miles away to within a few miles of their targets, that we seem mysteriously unable to use information technology to develop effective, sophisticated computer assistance for prescribers. Early problems with prescribing systems seem to have made individuals very sceptical about the role of computers. Perhaps they would be less sceptical if they had more insight into the fallibility of the human cortex.

\section{References}

1 Ferner RE. Is there a cure for drug errors? $B M J$ 1995; 311: 463-64.

2 Tully MP. Appropriate prescribing. Rev Clin Gerontol 1995; 6: 49-56.

3 Nolan L, O'Malley K. Prescribing for the elderly. Part I. Sensitivity of the elderly to adverse drug reactions. J Am Geriatr Soc 1988; 36: 142-49.

4 Williamson J, Chopin JM. Adverse reactions to prescribed drugs in the elderly: a multicentre investigation. Age Ageing 1980; 9: 73-80.

5 Trewin VF, Lawrence CJ, Veitch GBA, Luscombe DK. Prescribing patterns and iatrogenic disease, 10 years on. Care Elderly 1991; 3: 193-8.

6 Weintraub M. Compliance in the elderly. Ann Intern Med 1990; 6: 445-52.

7 Gosney M, Tallis RC. Prescription of contraindicated and interacting drugs in elderly patients admitted to hospital. Lancet 1984 i: 564-67.

8 Adams K, Al-Hamouz S, Edmond E, Tallis RC, Vellodi C, Lye MDW. Inappropriate prescribing in the elderly. J R Coll Physicians 1987; 21: 39-41.

9 Browne M, Tallis RC, Vellodi C, Al-Hamouz S, Edmond ED. A computer-assisted survey of contrainicated and interacting drugs in long-stay geriatric patients. Br J Pharm Pract 1987; 9: 250-54.

10 Gosney M, Vellodi C, Tallis R, Edmond E, AlHamouz S. Inappropriate prescribing in Part 3 residential homes for the elderly. Health Trends 1989; 21: 129-31.

11 Willcox SM, Himmelstein DU. Woolhandler S. Inappropriate drug prescribing for the communitydwelling elderly. JAMA 1994; 272: 292-96.

12 Tamblyn RM, McLeod PJ, Abrahamowicz $\mathrm{M}$ et al. Questionable prescribing for elderly patients in Quebec. Can Med Assoc J 1994; 150: 1801-809.

13 Lindley CM, Tully MP, Paramsothy V, Tallis RC. Inappropriate medication is a major cause of adverse drug reactions in elderly patients. Age Ageing 1992; 21: 294-300.

14 Tallis RC. Drug treatment of the elderly: a suitable case for (computer) treatment? In: Tallis RC, Caird FI eds. Advanced geriatric medicine, Volume 5. London: Pitman Publishing, 1986: 3-10. 